\title{
Influence of recycled polystyrene beads on cement paste properties
}

\author{
Maroua Maaroufi, Akli Younsi, Rafik Belarbi, Armelle Nouviaire \\ University of La Rochelle, LaSIE UMR CNRS 7356, La Rochelle, France
}

\begin{abstract}
In order to keep up with the requirements of sustainable development, there is a growing interest towards reducing the energy consumption in the construction and rehabilitation of buildings and the promotion of recycling waste in building materials. The use of recycled polystyrene beads in cement-based materials composition constitutes a solution to improve the insulation in buildings. This allows also limiting landfill by reusing the polystyrene waste. The aim of this study is to compare some properties and performances of a cement paste containing polystyrene beads to a reference paste designed with only the same cement. An experimental campaign was conducted and the obtained results showed that adding recycled polystyrene beads to a cement paste improves its hygro-thermal properties. Further studies are however necessary to better understand the real role of the polystyrene beads in the heat and mass transfers.
\end{abstract}

\section{Introduction}

In today's world, the need for quality housing is becoming more pressing, and it has become increasingly common to adopt alternative building materials that use waste or recycled materials, given the overexploitation of natural resources in the construction sector. Moreover, energy consumption in building continues to increase, and another difficulty to overcome is developing suitable materials in order to reduce this consumption. Enhancing the thermal properties of building materials is one way to contribute to improving energy efficiency in buildings.

Lightweight concrete is a good track for alternative building materials in modern construction applications. It greatly improves the technical, economical and environmental aspects of the construction sector. The use of lightweight concrete significantly reduces the load and the weight of the structures. Compared to ordinary concrete, it has many advantages such as: lower density, lower thermal conductivity, better fire resistance, improved durability properties and higher acoustic insulation characteristics. However, this type of concrete is associated with lower mechanical properties and a higher water demand due to the very porous structure of the material. It is generally used to make non-structural insulating items.

Expanded polystyrene (EPS) appears as a good choice to produce lightweight concrete given its good thermal properties, its very low density and its moisture resistance. It is a material commonly used for insulation and packaging of several products for protection purposes due to its flexible structure, impact absorption property and mechanical robustness. It is present in various industrial fields and is most often released into nature after its use. However, being non-biodegradable, it does not disappear by natural means and remains present in nature for many years. For this reason, the recycling of EPS, in its natural form or after some treatments, is beneficial to the economy and for the protection of the environment.

EPS is not poisonous because it does not perform chemical reaction under normal atmospheric conditions. It is not a nutrient for bacteria and fungi. Moreover, EPS is an environmental friendly material as it is recyclable and its components do not give harm to the nature and the ozone layer.

In the recent years, properties of polystyrene concrete were investigated in many studies:

- De Melo [1] found that incorporating EPS aggregates in mortar mixture improves the thermal performances and decreases the mechanical strength.

- Chikhi et al. [2] showed that increasing the amount of EPS chips in concrete mixture decreases the density and the thermal conductivity. The authors classify the soobtained material in the category of capillaroporous hygroscopic materials.

- Kaya and Kar [3] showed the same positive effect of incorporating EPS in concrete composition. They also found that the water absorption decreases with increasing the amount of EPS in the mixture. 
- Li et al. [4] and Ferrandiz-Mas et al. [5] highlighted that EPS improves the durability of the concrete.

In the present study, two cement-based materials were designed: a lightweight mortar, prepared by mixing EPS beads with cement, and a reference cement paste made with only the same cement. The objective was to assess the influence of EPS on the properties of the soobtained lightweight mortar and to extend thus the knowledge of polystyrene-based materials by providing informations about the microstructure using the adsorption/desorption isotherms.

\section{Materials and samples preparation}

Two types of cement-based materials were prepared with a water-to-binder ratio of 0.32: a lightweight mortar containing EPS beads (Fig.1) and a reference cement paste without EPS. Note that EPS contains $98 \%$ air and only $2 \%$ polystyrene. It has a very low density that varies between 20 and $30 \mathrm{~kg} / \mathrm{m}^{3}$ [6]. It is a thermoplastic material that has closed pores. EPS does not absorb liquid water.

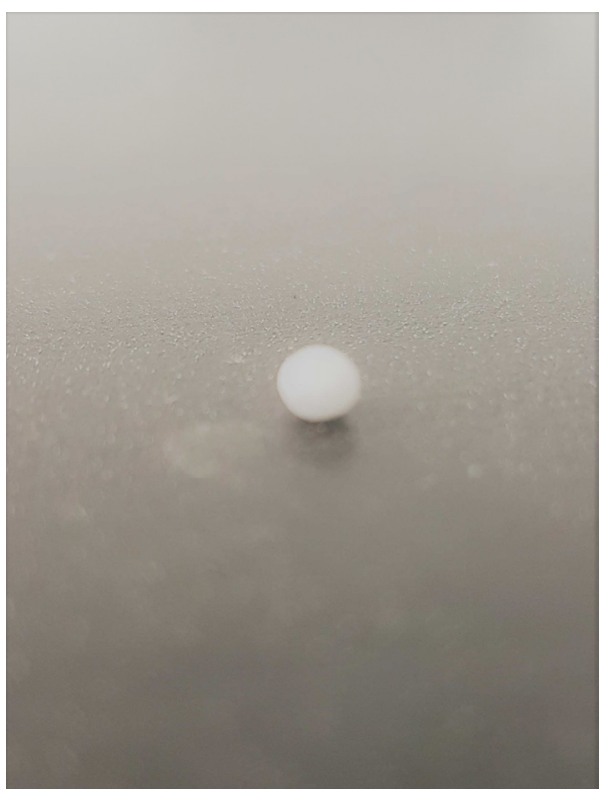

Fig. 1. Polystyrene bead

After casting in different molds, both the lightweight mortar and the reference cement paste were stored in endogenous conditions for 28 days before characterization.

\section{Experimental program}

\subsection{Compressive strength}

Compressive strength tests were conducted on $4 \mathrm{X} 4 \mathrm{X} 16 \mathrm{~cm}$ specimens after 28 days in endogenous conditions. Tests were carried out in a testing machine at a loading rate of $2.4 \mathrm{kN} / \mathrm{s}$ (Fig. 2).

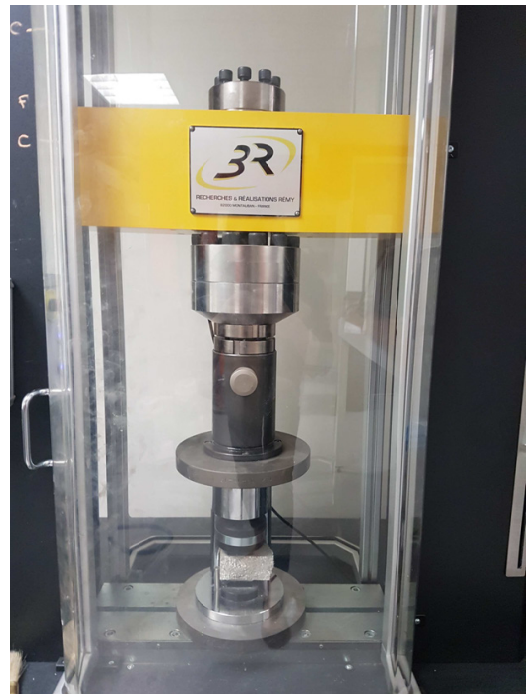

Fig. 2. Compressive strength testing machine

\subsection{Thermal conductivity}

The $\lambda$-Meter EP500e (Fig. 3) was used to measure the thermal conductivities. The apparatus operates according to the guarded hot plate method described in EN12664 and EN 12667 standards. This is the most commonly used method for measuring low values of thermal conductivity $\left(\lambda \leq 1 \mathrm{~W} / \mathrm{m}^{2} . \mathrm{K}\right)$, i.e. for insulating materials.

The sample is put between a hot plate and a cold one, and is submitted to a constant temperature gradient. The thermal conductivity is then calculated as follows:

$$
\lambda=\frac{Q \cdot d}{A \cdot \Delta T}
$$

with $\mathrm{Q}(\mathrm{W})$ the electrical power of the measuring heating; $\mathrm{d}(\mathrm{m})$ the thickness of the sample; $\mathrm{A}\left(\mathrm{m}^{2}\right)$ the transfer area and $\Delta \mathrm{T}(\mathrm{K})$ the temperature gradient.

In our case, $5.3 \mathrm{X} 15 \mathrm{X} 15 \mathrm{~cm}$ samples were used.

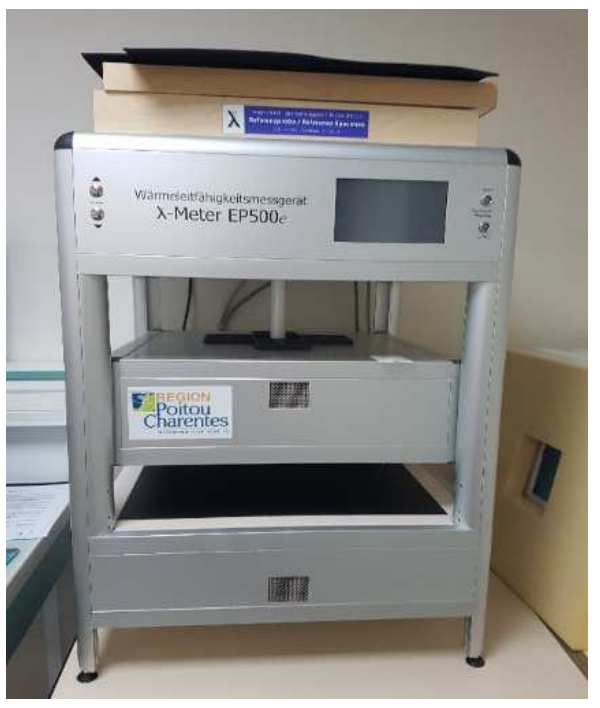

Fig. 3. $\lambda$-Meter EP500e 


\subsection{Heat capacity}

The heat capacity expresses the heat storage capacity of the material. It depends on temperature and was measured using a calorimeter Calvet BT 2.15 (Fig. 4). This technique (3D technique) is more accurate than micro-calorimetry or DSC ones. According to Calvet approach, the sample is completely surrounded by thermocouples. Such a design guarantees the measurement of the total heat exchange between the sample and the surroundings through the calorimetric detector.

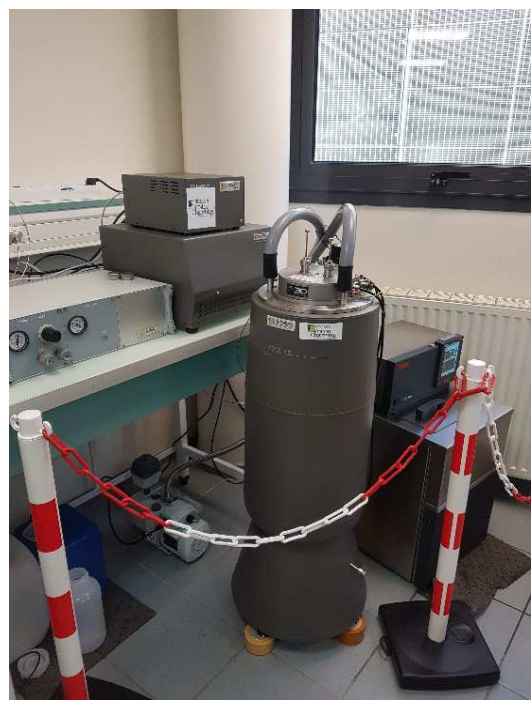

Fig. 4. Calorimeter Calvet BT 2.15

\subsection{Total porosity}

The total porosity was measured according to the French NF P18-459 standard, which is based on the water saturation of the samples under vacuum. However, this method is not suited to lightweight materials, especially those with polystyrene, which is hydrophobic and does not absorb water. For the determination of the polystyrene cement paste porosity, we used an empirical equation established by Kaya and Kar [3].

\subsection{Adsorption and desorption isotherms}

There are several techniques and devices for measuring water vapor sorption isotherms. The oldest one is the traditional gravimetric method, using saturated salt solutions to regulate the relative humidity. This method requires a long time to provide results. So we used this method with smaller samples and automatic humidity regulator using Vapor Soption Analyser (VSA, Decagon) shown in Fig. 5. Another device was used based on volumetric method (Belsorp Aqua3 in Fig. 6).

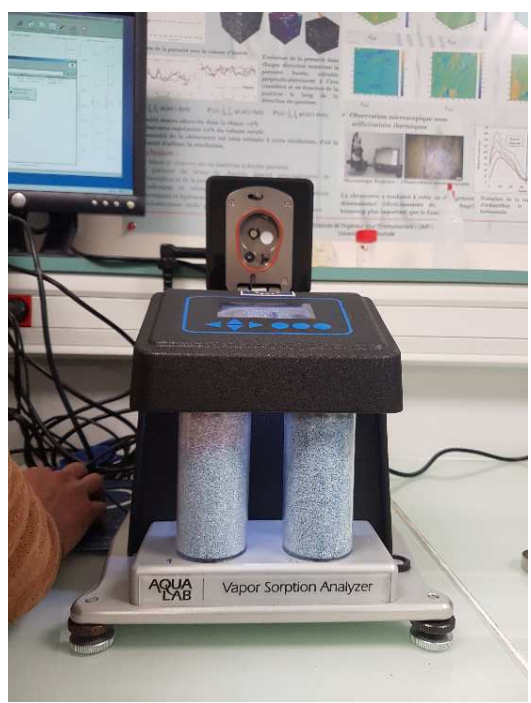

Fig. 5. Vapor sorption analyser (VSA)

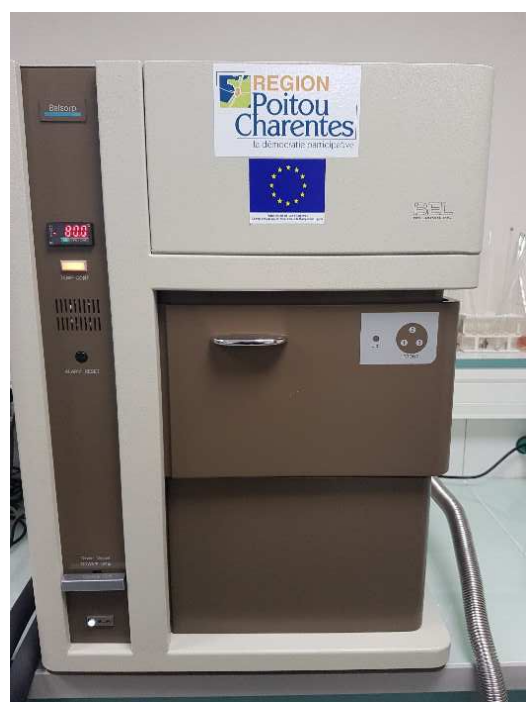

Fig. 6. BELSORP aqua 3

\section{Results and discussion}

\subsection{Compressive strength}

As expected, the compressive strength decreases when EPS beads are added (Fig. 7). Indeed, the 28-day compressive strength of the reference cement paste is equal to $22 \mathrm{MPa}$ while it is equal to only $4 \mathrm{MPa}$ for the lightweight mortar. This result is in good agreement with the literature since lightweight aggregates, and polystyrene in particular, are known to alter the mechanical properties of cementitious materials. 


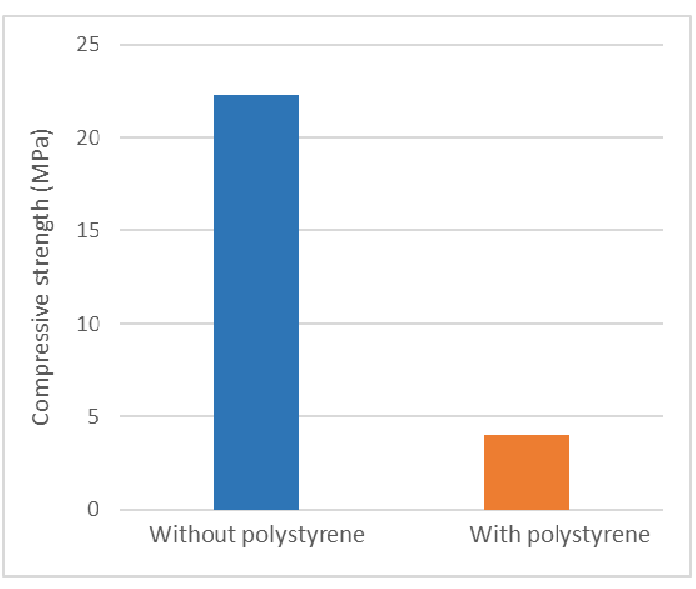

Fig. 7.28-days compressive strength

\subsection{Thermal conductivity}

Fig. 8 shows that the thermal conductivity decreases considerably with the addition of EPS beads. At $23^{\circ} \mathrm{C}$, the thermal conductivity is equal to $383 \mathrm{~mW} / \mathrm{m}^{\circ} \mathrm{K}$ for the reference cement paste, and it goes down to $142 \mathrm{~mW} / \mathrm{m}^{\circ} \mathrm{K}$ for the lightweight mortar. This can be explained by the insulating behavior of the EPS beads that contain $98 \%$ of air and that have a very low thermal conductivity $\left(\lambda=0.04 \mathrm{~W} / \mathrm{m}^{\circ} \mathrm{K}[7]\right)$.

Our polystyrene cement paste (lightweight mortar) has a good thermal insulating performance compared to some values from the literature (Table 1).

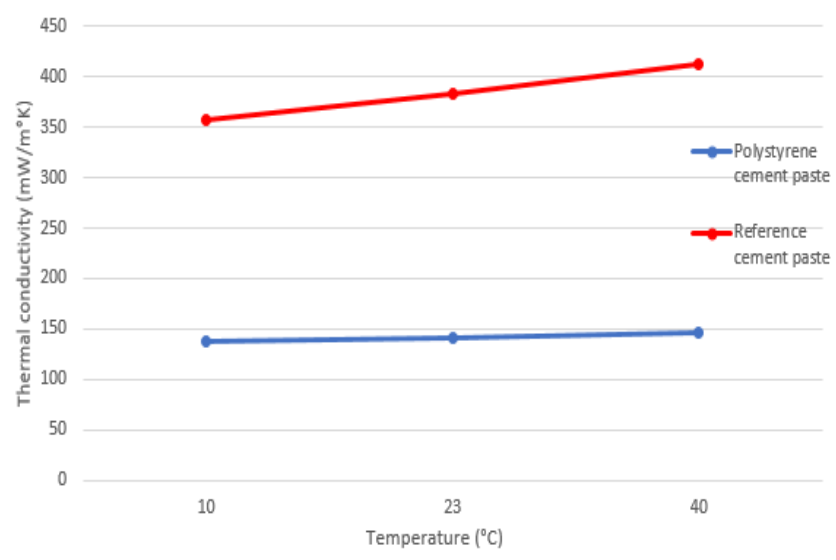

Fig. 8. Thermal conductivity

\subsection{Heat capacity}

Table 1 shows that the presence of EPS beads improves the specific heat capacity of the cement paste. This means that the lightweight mortar has a better heat storage capacity, and confirms the thermal insulating behavior of this material.

\subsection{Total porosity}

The obtained water porosities after 28 days in endogenous conditions are given in Table 1 . The results show that the porosity increases when EPS beads are added. This is due to the high porosity of the beads which is assessed to be equal to $95 \%$. Note however that the porosity of the polystyrene cement paste was obtained using an empirical equation. Therefore, we should find a more suitable technique to determine the porosity of this kind of lightweight material.

\begin{tabular}{|c|c|c|c|c|}
\hline Material & $\begin{array}{c}\text { Thermal } \\
\text { conductivity } \\
\left(\mathrm{mW} / \mathrm{m}^{\circ} \mathrm{K}\right) \text { at } \\
23^{\circ} \mathrm{C}\end{array}$ & $\begin{array}{c}\text { Heat } \\
\text { capacity } \\
\left(\mathrm{J} / \mathrm{Kg}^{\circ} \mathrm{K}\right) \\
\text { at } 20^{\circ} \mathrm{C} \\
\end{array}$ & $\begin{array}{c}\text { Total } \\
\text { porosity } \\
(\%)\end{array}$ & Literature \\
\hline $\begin{array}{l}\text { Polystyrene } \\
\text { cement paste }\end{array}$ & 142 & $920-1030$ & 57 & $\begin{array}{c}\text { Present } \\
\text { work }\end{array}$ \\
\hline $\begin{array}{c}\text { Reference } \\
\text { cement paste }\end{array}$ & 383 & $900-920$ & 33 & $\begin{array}{c}\text { Present } \\
\text { work }\end{array}$ \\
\hline $\begin{array}{c}\text { Cork based } \\
\text { cement paste }\end{array}$ & 270 & & 37.5 & {$[1]$} \\
\hline $\begin{array}{l}\text { Polystyrene } \\
\text { cement paste }\end{array}$ & 230 & & & [1] \\
\hline $\begin{array}{c}\text { Cork based } \\
\text { mortar }\end{array}$ & $190-320$ & & & [8] \\
\hline $\begin{array}{c}\text { Polystyrene } \\
\text { foamed } \\
\text { concrete }\end{array}$ & $85-156$ & & & [9] \\
\hline $\begin{array}{l}\text { Polystyrene } \\
\text { concrete }\end{array}$ & 930 & 950 & 60 & [2] \\
\hline $\begin{array}{c}\text { Cork } \\
\text { gypsum } \\
\text { composite }\end{array}$ & $110-124$ & $\begin{array}{c}1267- \\
1287\end{array}$ & & [11] \\
\hline $\begin{array}{c}\text { Hemp } \\
\text { concrete }\end{array}$ & 124 & 1000 & 76 & [12] \\
\hline
\end{tabular}

Table 1. Properties of our materials and others from literature

\subsection{Adsorption and desorption isotherms}

The water vapor adsorption/desorption isotherms obtained with the volumetric method (Belsorp) are given in Fig. 9. The two isotherms exhibit the same behavior and tendency. This similitude is due to the hydrophobic property of the EPS beads and to their closed poral structure. The beads do not adsorb water vapor and have no impact on the isotherms.

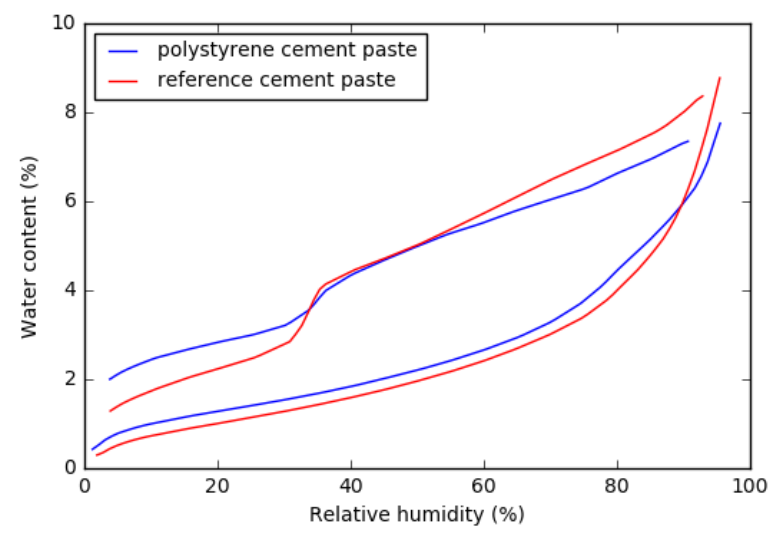

Fig. 9. Adsorption and desorption isotherms (BELSORP)

Sorption isotherms curves of two experimental techniques: the gravimetric method (VSA) and the volumetric method (BELSORP aqua 3) are shown in Figure 10. A good agreement between these results is observed. 


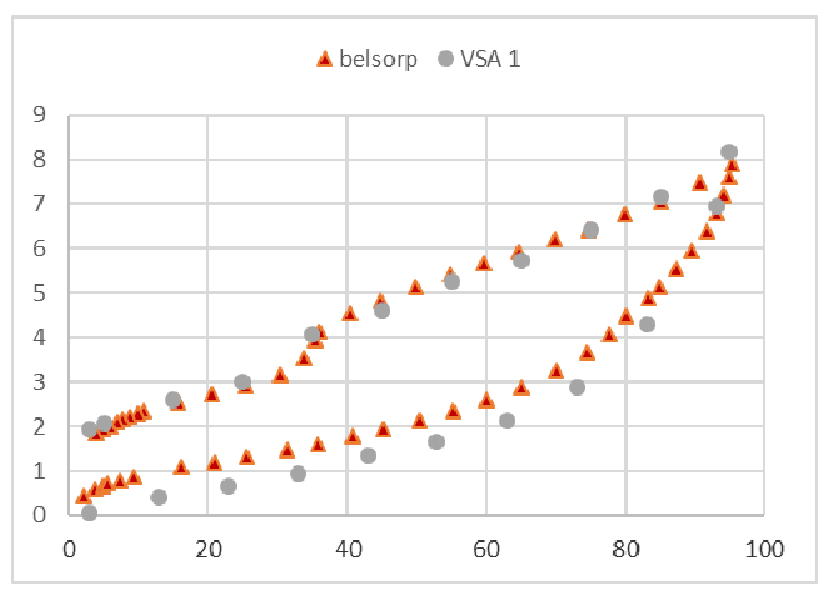

Fig. 10. Comparison of polystyrene cement isotherms with the different techniques

\section{Conclusion}

The objective of this work was to assess the influence of the polystyrene beads on the mechanical and hygrothermal properties of cement pastes, along with their microstructure and porosity. The main conclusions are:

- The compressive strength decreases by adding the polystyrene beads, which are lightweight aggregates and composed of $98 \%$ of air.

- Thermal conductivity of the polystyrene cement paste is lower than the reference cement paste, due to the insulating behavior of the polystyrene beads.

- The specific heat capacity is higher for the polystyrene cement paste, because the polystyrene has a good heat storage capacity.

- The presence of the polystyrene beads highly increases the total porosity of the cement paste, because of their high porosity.

- The water vapor isotherms do not show a notable impact of the beads on the cement pastes, because of the hydrophobic nature and the closed poral structure of polystyrene.

\section{Acknowledgements}

The authors would like to express their sincere thanks to Kamilia Abahri and Rabah Hamzaoui for their kind support and helpful discussions.

This work was funded by the Region Aquitaine, Limousin, Poitou-Charentes through European and National Program CPER-FEDER "Bâtiment Durable 2015-2020".

\section{References}

1. Humberto Fernandes Sequeira Borges de Melo, master degree report, technical university of Lisbon, Portugal (2014)

2. A. Chikhi, A. Belhamri, P. Glouannec, A. Magueresse, Journal of building engineering 7, 183193 (2016)
3. A. Kaya, F. Kar, Construction and building materials 105, 572-578 (2016)

4. Y. Li, N. Liu, B. Cheng, Materials and structures 48, 269-276 (2013)

5. V. Ferrándiz-Mas, E. García-Alcocel, Construction and building materials 46, 175-182, (2013)

6. P.L.N. Fernando, M.T.R. Jayasinghe, C. Jayasinghe, Construction and building materials 139, 45-51, (2017)

7. M. Y. Ferroukhi, K. Abahri, R. Belarbi, K. Limam, A. Nouviaire, Heat and mass transfer 52, 2257-2269 (2015)

8. A. Moreira, J. António, A. Tadeu, Cement and Concrete Composites 49, 1-8 (2014)

9. A. A. Sayadi, J. V. Tapia, T. R. Neitzert, G. C. Clifton, Construction and building materials 112, 716-724 (2016)

10. C. Ma, B. Chen, Construction and building materials 123, 106-114 (2016)

11. A. Cherki, B. Remy, A. Khabbazi, Y. Jannot, D. Baillis, Construction and building materials 54, 202209 (2014)

12. D. Lelièvre, PhD thesis, University of Bretagne-Sud (2016)

13. Ecomatériaux et isolation, Construction et travaux publics | Techniques du bâtiment : le second œuvre et les lots techniques (2012) 